\title{
Editorial Message
}

\section{The 25th anniversary of Neurosciences Journal}

This April issue marks the journal's 25th anniversary of continuous publications. The Neurosciences Journal (NSJ) started in April 1996 as an official bulletin from the Department of Neurosciences_affiliated to Prince Sultan Military Medical City-following increased submissions of neurosciences papers to the Saudi Medical Journal (SMJ). Initially, the journal started was biyearly and then rapidly turned into a quarterly publication. The founding editor of the journal Maj. Gen.

Professor Saleh Al-Deeb, Maj. Gen. Dr. Khalaf Al-Moutaery (God bless his soul) and Professor Basim Yaqubhad the honor and opportunity to establish the basin for neurosciences research and, without their visions, dreams, and goals the journal may not have existed.

This vision from birth to growth and success would not come to reality without many contributing pillars. His Royal Highness (HRH) Prince Sultan bin Abdul-Aziz (God bless his soul)—who had blessed and supported both SMJ and NSJ editorial office from the very beginning, was the journal's founding patron. This blessing continued with the current patron HRH Prince Mohammed Bin Salman bin Abdulaziz Al Saud, whose vision, support, and determination to build a thriving country gave NSJ further drive to achieve its ambitions and be at the level of 2030 vision. The sky is NSJ's limit when it comes to its dreams and achievements.

As associate editors of NSJ, we would like to present our special thanks to our reviewers, advisory boards, and editorial boards for their valuable comments and generous volunteer effort to maintain the standards of the journal's publications. We would also like to take this opportunity to thank our editors for their energy and enthusiasm in promoting the journal locally and internationally, and our present and previous staff for their dedication and commitment to the journal's work. Furthermore, we do not forget to show our grateful appreciation to the administration of both the Medical Services Department and Prince Sultan Military Medical City for their endless help and support.

From the start, the leadership dedication has been the cornerstone of NSJ's success and ongoing development and improvement. In 2000, the journal established its own website where readers can view, read, and download articles in PDF format. In 2006, the journal received approval for indexing by Thomson Scientific (formerly known as Thomson ISI), followed by MEDLINE's including and indexing its contents and by Pub Med's incorporating its English abstracts in July 2010. In 2016, NSJ's articles were indexed in the Pub Med Central. The journal started to expand its visibility using many databases. In 2018, a new theme and logo were implemented on the website's home page to match the changes that occurred in the journal cover and layout. A switch to a new domain (nsj.org.sa) was made to increase the journal's visibility. Furthermore, a redesign of the website took place to make it mobile-friendly. A major step occurred by the end of 2018 as a new online system of submission was launched-the ScholarOne Manuscripts ${ }^{\text {TM }}$ System. This new system has improved and accelerated everyday peer-review tasks from manuscripts' submissions to final decisions. 


\section{Editorial Message}

During the 25 years, the contribution of local publications in terms of both quantity and quality has increased. In 2007, the percentage of articles from Saudi Arabia was $24 \%$, but it rose to $45 \%$ in 2012 , and more than $50 \%$ of our published articles are from the Kingdom of Saudi Arabia at present.

As part of its mission to encourage local research and publications, NSJ focused on reaching out to respected local scientific neurosciences organizations. Co-operative treaties were signed with a number of Saudi societies, including the Saudi Association of Neurological Surgery, Saudi Neurology Society, Saudi Stroke Society, Saudi Neuro-Pediatric Society, Saudi Epilepsy Society and Saudi Neuro-Critical Care Chapter

NSJ is still committed to being a successful establishment for disseminating neuroscientific research to the highest level locally, regionally, and internationally.
Waleed Khoja

Associate Editor
Khalid Hundallah Associate Editor 